\title{
Comparison of desflurane and sevoflurane on postoperative recovery quality after tonsillectomy and adenoidectomy in children
}

\author{
XIAOLE WU, CHENGJING SHAN, BEI PENG, XUXU SHI, FENGCHAO ZHANG and JUNHUA CAO
}

Department of Anesthesiology, Xuzhou Children's Hospital, Xuzhou Medical University, Xuzhou, Jiangsu 221006, P.R. China

Received November 15, 2018; Accepted March 20, 2019

DOI: $10.3892 /$ etm.2019.7467

\begin{abstract}
Comparison of desflurane and sevoflurane on the postoperative recovery quality after tonsillectomy and adenoidectomy in children was carried out. A retrospective analysis was performed on the medical records of 165 children who underwent tonsil and adenoid radiofrequency ablation under low-temperature plasma and were admitted to the Xuzhou Children's Hospital, Xuzhou Medical University from February 2014 to May 2017. In total, 79 children with sevoflurane anesthesia were in the sevoflurane group, and 86 children with desflurane anesthesia in the desflurane group. The non-invasive blood pressure (NIBP), heart rate (HR) and oxygen saturation $\left(\mathrm{SpO}_{2}\right)$ level, the postoperative sedation (Ramsay) scores, the modified objective pain score (MOPS) of children were recorded. The pediatric anesthesia emergence delirium (PAED) scores of children were recorded. Children in the sevoflurane group had longer operation time, anesthesia time, extubation time and coincidence time than those in the desflurane group $(\mathrm{P}<0.05)$. At the beginning of operation (t1), $10 \mathrm{~min}$ after operation (t2), at the time of entering anesthesia recovery room (t3), at the time of tracheal catheter extubated (t4), 10 min after extubation (t5), and at the time of leaving the anesthesia recovery room (t6), children in the sevoflurane had higher NISBP and NIDBP, lower HR than those in the desflurane group $(\mathrm{P}<0.05)$. At the time of the tracheal catheter extubation $(\mathrm{c} 2)$, $10 \mathrm{~min}$ after extubation (c3), $30 \mathrm{~min}$ after extubation (c4), children in the sevoflurane group had lower Ramsay scores and higher PAED scores than those in the desflurane group $(\mathrm{P}<0.05)$. More suitable as an anesthetic maintenance drug for tonsillectomy and adenoidectomy in children, desflurane has a better anesthetic effect and is safer. In addition, children with desflurane anesthesia have high postoperative
\end{abstract}

Correspondence to: Dr Junhua Cao, Department of Anesthesiology, Xuzhou Children's Hospital, Xuzhou Medical University, 18 Suti North Road, Quanshan, Xuzhou, Jiangsu 221006, P.R. China

E-mail: cyugug@163.com

Key words: desflurane, sevoflurane, children, tonsil, adenoid, resection, recovery quality recovery quality and quick recovery in the short term, with better sedative and analgesic effects. Therefore, it is worthy of promotion in clinic practice.

\section{Introduction}

As important parts of the inner ring of the pharyngeal lymphatic ring, the tonsil and the adenoid are the first immune line of defense for the upper respiratory tract of the human body. When children's immune function is low, tonsil and adenoid tissues cause hypertrophy and chronic inflammation once stimulated by external pathogens (1). In recent years, children with tonsil and adenoid hypertrophy are very common (2). Tonsil hypertrophy leads to upper respiratory tract infection in children, and local inflammation, thereby resulting in systemic diseases (3). It also causes poor breathing in children, and even obstructive sleep apnea syndrome, which affects the growth and development of children (4). Adenoid hypertrophy oppresses the auditory tube that results in secretory otitis media (5). The excessive secretion of ear canal blocks the nostrils, and causes sinusitis, rhinitis and other complications of a series of adjacent organs, seriously affecting the physical and mental health of children. With the advancement of medical technology, tonsil hypertrophy and adenoid hyperplasia have been gradually valued by number of parents. The low-temperature plasma radiofrequency ablation technique is the most commonly used for excising the tonsil and the adenoid (6).

Children undergoing pediatric operation have poor operative compliance. The low-temperature plasma radiofrequency ablation technique requires endotracheal intubation, which has a larger intensity of operative stimulation, so deeper general anesthesia is required for operation (7). At present, respiratory inhalation anesthesia, and muscle, intravenous anesthesia are two commonly used general anesthesia. Both of them finally inhibit the central nervous system (8). Inhalation anesthesia is the most commonly used anesthesia for pediatric clinical operations. Sevoflurane is a widely used fluorine-containing volatile inhalation general anesthetic in clinical practice (9), with a blood and air partition coefficient approximately between $0.60 \pm 0.07$ and $0.686 \pm 0.047$. With easy operation, stability during operation and good controllability, it is easy to control anesthesia depth, with less stimulation to the respiratory tract, so it is increasingly 
used in clinical practice (10). However, sevoflurane has an irritating effect on the central nervous system, leading to frequent postoperative agitation (11). Agitation may cause the tearing of the operative wound in children, and physical harm to them. Desflurane is a third-generation halogen new gas inhalation general anesthesia, commonly used in pediatric operations for anesthesia (12). It has almost no effect on the circulatory system. The liver and the kidney in the body are hardly involved in its metabolism, which has little impact on the liver and kidney (13). However, desflurane for anesthesia induction has airway irritation, and easily cause laryngeal spasm, cough, increase in secretion, and pharyngitis during anesthesia (14). Therefore, desflurane is clinically less used for the anesthesia induction in clinical practice but commonly used in children to maintain anesthesia.

In the management of general anesthesia, anesthesia recovery occupies a very important position, and the anesthesia recovery quality widely concerns anesthesiologists. Important aspects of good anesthesia recovery quality include low postoperative pain, high comfort degree in children, no obvious adverse reactions during the extubation period, stable breathing after anesthesia recovery, short recovery and extubation time (15). Therefore, in this study, a retrospective analysis was performed on the effects of desflurane and sevoflurane on the postoperative recovery quality after tonsillectomy and adenoidectomy in children, to find anesthetic drugs more suitable for tonsillectomy and adenoidectomy in children, and provide clinical references.

\section{Patients and methods}

General information. A retrospective analysis was performed on the clinical medical records of 165 children who underwent tonsillectomy and/or adenoidectomy and were admitted to the Xuzhou Children's Hospital, Xuzhou Medical University (Xuzhou, China) from February 2014 to May 2017. Among them, 79 children were anesthetized with sevoflurane as the sevoflurane group, with an average age of $5.34 \pm 1.52$ years. Another 86 children were anesthetized with desflurane as the desflurane group, with an average age of $5.46 \pm 1.45$ years. The study was conducted after approval by the Medical Ethics Committee of Xuzhou Children's Hospital, Xuzhou Medical University. Both the family and the patients were informed and the parents signed an informed consent form.

Inclusion and exclusion criteria. Inclusion criteria: with tonsil or adenoid hypertrophy; aged 3-7 years; with a body weight of $10-30 \mathrm{~kg}$; male or female. Exclusion criteria: those with dysgnosia; those with respiratory inhibition diseases or bronchial asthma; those with severe circulatory system or blood system dysfunction; those with a history of anesthesia allergy.

Experimental methods. Children in the two groups were treated with intravenous general anesthesia for the operation. Venous blood collection was performed before operation to detect leukocytes and other blood routine indicators. Twenty-four hours before the operation, the responsible nurse punctured the indwelling needle to establish an intravenous infusion channel for intraoperative use. Six hours before the operation, all children were fasted. Four hours before the operation, they were disallowed to consume any liquids. At the day of operation, parents were required to accompany children into the operation waiting area. When waiting, the parents embraced the children and actively communicated with them to relieve their tension and reduce their psychological burdens. Individual children with preoperative agitation who did not cooperate with the nurse to enter the operating room were intravenously infused with atropine (Hubei Xinghua Pharmaceutical Co., Ltd., Hubei, China, guoyaozhunzi: H42020590) $0.01 \mathrm{mg} / \mathrm{kg}$, and immediately with ketamine (Xi'an Hanfeng Pharmaceutical Co., Ltd., Xi'an, China, guoyaozhunzi: H20054748) $1 \mathrm{mg} / \mathrm{kg} 60 \mathrm{sec}$ later. After they were unconscious and fell asleep smoothly, children were taken into the operating room. After entering the operating room, the mask was immediately substituted with oxygen supply, and the monitoring device was connected to detect the HR, electrocardiogram (ECC), NIBP and $\mathrm{SpO}_{2}$ of children. After the monitoring device was properly connected, children were intravenously administered fentanyl (Sinopharm Group Industrial Co., Ltd. Langfang Branch, Langfang, China, guoyaozhunzi: H20123297) $2 \mu \mathrm{g} / \mathrm{kg}$, and given rocuronium bromide (Zhejiang Xianju Pharmaceutical Co., Ltd., Zhejiang, China, guoyaozhunzi: H20123188) $0.4 \mathrm{mg} /$ $\mathrm{kg}$ and atracurium (Zhejiang Xianju Pharmaceutical Co., Ltd., guoyaozhunzi: H20090202) $0.1 \mathrm{mg} / \mathrm{kg} 60 \mathrm{~min}$ later for the anesthesia induction. The tracheal intubation was performed after drugs were fully effective. Children in the sevoflurane group continued to be given sevoflurane (Jiangsu Hengrui Pharmaceutical Co., Ltd., Jiangsu, China, guoyaozhunzi: H2004077) at a concentration of approximately 2-3\% for anesthesia maintenance, children in the desflurane group were given desflurane (Baxter Healthcare, Guayama, Puerto Rico, guoyaozhunzi: H20090201) at a concentration of 6-10\% for anesthesia maintenance. An anesthesia apparatus was connected to regulate children's breathing, and the operation began after the minimum alveolar anesthetic concentration was controlled at 1.0-1.6, the oxygen flow at $1-21 / \mathrm{min}$, the respiratory rate at 20-28 times/min, and the end-tidal carbon dioxide partial pressure maintained at $30-38 \mathrm{mmHg}$. After the operation, children were immediately stopped from medication and sent to the anesthesia recovery room. Their respiratory tract and oral secretions were cleaned up, and they were cared for by dedicated medical staff. When children had spontaneous breathing, with a respiratory rate $\geq 18$ times/ min and an inhaled air $\mathrm{SpO}_{2} \geq 95 \%$, and had spontaneous limb activity, cough and swallowing, they were considered as anesthesia recovery. At this time, the tracheal catheter was extubated. When children were completely awake, with stable vital signs, they were sent back to the intensive care unit.

\section{Outcome measures}

Time required for each project of operation. The time required from injection-induced anesthesia to be effective (onset time of anesthesia), residence time in the operating room (operation time), time required from entering the anesthesia recovery room to anesthesia recovery (recovery time), time required from anesthesia recovery to extubate the tracheal catheter (extubation time) and time spent in the anesthesia recovery room (coincidence time) of children in the two groups were recorded. 
Table I. Comparison of general clinical data of children in two groups [n (\%)] (mean \pm SD).

\begin{tabular}{lcccr}
\hline Category & Sevoflurane group $(\mathrm{n}=79)$ & Desflurane group $(\mathrm{n}=86)$ & $\chi^{2} / \mathrm{t}$ value & P-value \\
\hline Sex & & & 0.108 & 0.756 \\
Male & $36(45.57)$ & $37(43.02)$ & & \\
Female & $43(54.43)$ & $49(56.98)$ & & \\
Age $($ years $)$ & $5.34 \pm 1.52$ & $5.46 \pm 1.45$ & 0.519 & 0.605 \\
Height $(\mathrm{cm})$ & $105.35 \pm 23.24$ & $103.93 \pm 24.71$ & 0.379 & 0.705 \\
Weight $(\mathrm{kg})$ & $21.34 \pm 6.33$ & $22.01 \pm 7.19$ & 0.633 & 0.528 \\
Preoperative leucocyte $\left(\mathrm{x} 10^{9} / \mathrm{l}\right)$ & $21.46 \pm 5.38$ & $22.84 \pm 5.82$ & 1.577 & 0.117 \\
Preoperative erythrocyte $\left(\mathrm{x} 10^{12} / \mathrm{l}\right)$ & $4.65 \pm 0.31$ & $4.58 \pm 0.36$ & 1.333 & 0.184 \\
Preoperative platelet $\left(\mathrm{x} 10^{9} / \mathrm{l}\right)$ & $342.45 \pm 98.46$ & $338.48 \pm 101.93$ & 0.254 & 0.800 \\
Preoperative hemoglobin $(\mathrm{g} / \mathrm{l})$ & $125.95 \pm 18.54$ & $128.51 \pm 16.38$ & 0.942 & 0.348 \\
\hline
\end{tabular}

Table II. Comparison of time required for each project of operation between two groups of children (mean \pm SD).

\begin{tabular}{lcccc}
\hline Category (min) & Sevoflurane group $(\mathrm{n}=79)$ & Desflurane group $(\mathrm{n}=86)$ & $\mathrm{t}$ value & P-value \\
\hline Onset time of anesthesia & $8.45 \pm 3.53$ & $8.96 \pm 2.21$ & 1.122 & 0.264 \\
Operation time & $38.75 \pm 10.86$ & $35.43 \pm 8.54$ & 2.192 & 0.030 \\
Recovery time & $16.43 \pm 6.99$ & $13.83 \pm 5.27$ & 2.711 & 0.007 \\
Extubation time & $9.52 \pm 4.65$ & $7.43 \pm 3.21$ & 3.382 & 0.001 \\
Coincidence time & $25.95 \pm 11.64$ & $21.26 \pm 8.48$ & 2.975 & 0.003 \\
\hline
\end{tabular}

Operative monitoring indicators. The NIBP, $\mathrm{HR}$ and $\mathrm{SpO}_{2}$ of children in the two groups were recorded at $\mathrm{t} 0, \mathrm{t} 1, \mathrm{t} 2, \mathrm{t} 3, \mathrm{t} 4$, t5 and $\mathrm{t} 6$.

Evaluation criteria for postoperative recovery quality. Postoperative sedation evaluation: According to Ramsay score (16), the sedation degree of children in the two groups was evaluated at c1, c2, c3, c4 and c5. Postoperative pain evaluation: According to the MOPS (17) criteria, the pain of children in the two groups was evaluated at b1, b2, b3, b4, b5 and b6. Postoperative agitation evaluation: According to the PAED (18) criteria, the agitation of children in the two groups was evaluated at a1, a2, a3, a4, a5 and a6.

Statistical analysis. SPSS17.0 [Yiyun (Shanghai) Information Technology Co., Ltd., Shanghai, China] was used for statistical analysis. Measurement data were expressed as mean \pm standard deviation (mean $\pm \mathrm{SD}$ ), and analyzed by t-test. Enumeration data were expressed as rate (\%), and Chi-square test was also used. $\mathrm{P}<0.05$ was considered to indicate a statistically significant difference.

\section{Results}

Baseline data of children. There were no significant differences in the sex, age, height, weight, preoperative leucocyte value, preoperative erythrocyte value, preoperative platelet value and preoperative hemoglobin value of children between the sevoflurane group and the desflurane group $(\mathrm{P}>0.05)$ (Table I).
Time required for each project of operation in two groups of children. There was no significant difference in the onset time of anesthesia of children between the sevoflurane group and the desflurane group $(\mathrm{t}=1.122, \mathrm{P}=0.264)$. Children in the desflurane group had shorter operation time than those in the sevoflurane group $(\mathrm{t}=2.192, \mathrm{P}=0.030)$; shorter recovery time than those in the sevoflurane group $(\mathrm{t}=2.711, \mathrm{P}=0.007)$; shorter extubation time than those in the sevoflurane group $(\mathrm{t}=3.382$, $\mathrm{P}=0.001)$; shorter coincidence time than those in the sevoflurane group $(\mathrm{t}=2.975, \mathrm{P}=0.003)$ (Table II).

Operative monitoring indicators of children in two groups. The results of the study showed that at 0 , there were no significant differences in the NISBP and NIDBP of children between the sevoflurane group and the desflurane group $(\mathrm{P}>0.05)$. At $\mathrm{t} 1, \mathrm{t} 2, \mathrm{t} 3, \mathrm{t} 4, \mathrm{t} 5$ and $\mathrm{t} 6$, children in the sevoflurane had higher NISBP and NIDBP than those in the desflurane group $(\mathrm{P}<0.05)$. At $\mathrm{t} 0$ and $\mathrm{t} 6$, there was no significant difference in the HR of children between the sevoflurane group and the desflurane group $(\mathrm{P}>0.05)$. At $\mathrm{t} 1, \mathrm{t} 2, \mathrm{t} 3, \mathrm{t} 4$ and $\mathrm{t} 5$, children in the sevoflurane group had lower HR than those in the desflurane group $(\mathrm{P}<0.05)$. At $\mathrm{t} 0, \mathrm{t} 4, \mathrm{t} 5$ and $\mathrm{t} 6$, there was no significant difference in the $\mathrm{SpO}_{2}$ of children between the sevoflurane group and the desflurane group $(\mathrm{P}>0.05)$. At $\mathrm{t} 1, \mathrm{t} 2$ and $\mathrm{t} 3$, children in the sevoflurane group had lower $\mathrm{SpO}_{2}$ than those in the desflurane group $(\mathrm{P}<0.05)$ (Fig. 1).

Postoperative sedation of children in two groups. The results of the study showed that at $\mathrm{c} 1$ and $\mathrm{c} 5$, there was no significant 


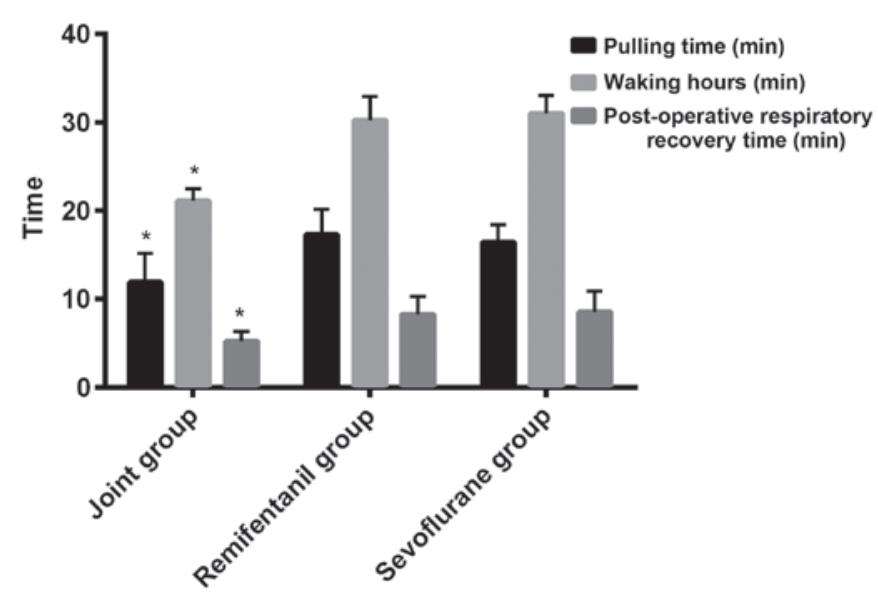

Figure 1. Comparison of life monitoring indicators of children between the sevoflurane and desflurane groups. At t0, there were no significant differences in the NISBP and NIDBP of children between the sevoflurane and desflurane groups $(\mathrm{P}>0.05)$. At t1, t2, t3, t4, t5 and t6, children in the sevoflurane group had higher NISBP and NIDBP than those in the desflurane group $(\mathrm{P}<0.05)$. At $\mathrm{t} 0$ and $\mathrm{t} 6$, there was no significant difference in the $\mathrm{HR}$ of children between the sevoflurane group and the desflurane group $(\mathrm{P}>0.05)$. At $\mathrm{t} 1, \mathrm{t} 2, \mathrm{t} 3, \mathrm{t} 4$ and $\mathrm{t} 5$, children in the sevoflurane group had lower HR than those in the desflurane group $(\mathrm{P}<0.05)$. At $\mathrm{t} 0, \mathrm{t} 4, \mathrm{t} 5$ and $\mathrm{t} 6$, there was no significant difference in the $\mathrm{SpO}_{2}$ of children between the sevoflurane group and the desflurane group $(\mathrm{P}>0.05)$. At $\mathrm{t} 1, \mathrm{t} 2$ and $\mathrm{t} 3$, children in the sevoflurane group had lower $\mathrm{SpO}_{2}$ than those in the desflurane group $(\mathrm{P}<0.05)$. ${ }^{*} \mathrm{P}<0.05$, compared to the sevoflurane group, the difference is statistically significant.

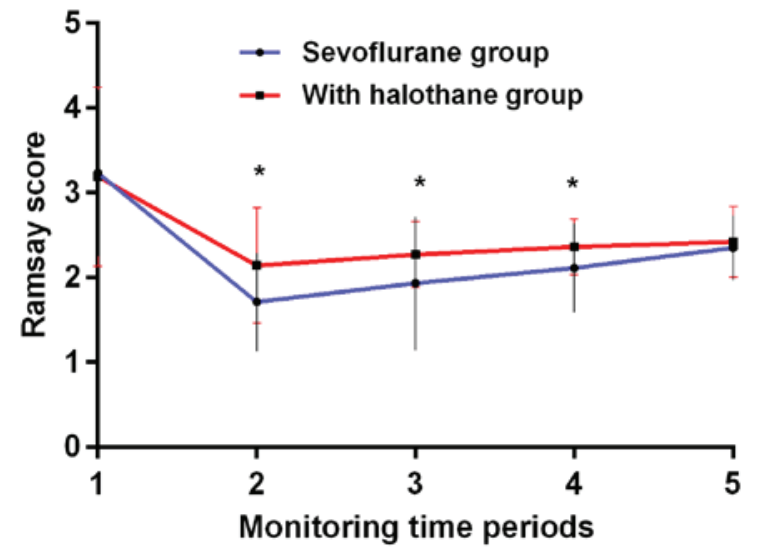

Figure 2. Comparison of Ramsay sedation scores of children between the two groups. The sedation of children in the two groups was evaluated according to the Ramsay sedation scoring criteria. The results showed that at $\mathrm{c} 1$ and c5, there was no significant difference in the Ramsay scores of children between the sevoflurane group and the desflurane group $(\mathrm{P}>0.05)$. At $\mathrm{c} 2, \mathrm{c} 3$ and $\mathrm{c} 4$, children in the sevoflurane group had lower Ramsay scores than those in the desflurane group $(\mathrm{P}<0.05)$. ${ }^{*} \mathrm{P}<0.05$, compared to the sevoflurane group, the difference is statistically significant.

difference in the Ramsay scores of children between the sevoflurane and desflurane groups $(\mathrm{P}>0.05)$. At $\mathrm{c} 2$, the Ramsay score of children was $(1.71 \pm 0.58)$ in the sevoflurane group, lower than $(2.14 \pm 0.68)$ in the desflurane group $(t=4.351$, $\mathrm{P}<0.001)$. At c 3 , the Ramsay score of children was $1.93 \pm 0.79$ in the sevoflurane group, lower than the $2.27 \pm 0.39$ in desflurane group $(\mathrm{t}=3.549, \mathrm{P}=0.001)$. At $\mathrm{c} 4$, the Ramsay score of children was $2.11 \pm 0.53$ in the sevoflurane group, lower than the $2.36 \pm 0.33$ in desflurane group $(\mathrm{t}=3.669, \mathrm{P}<0.001)$ (Fig. 2).

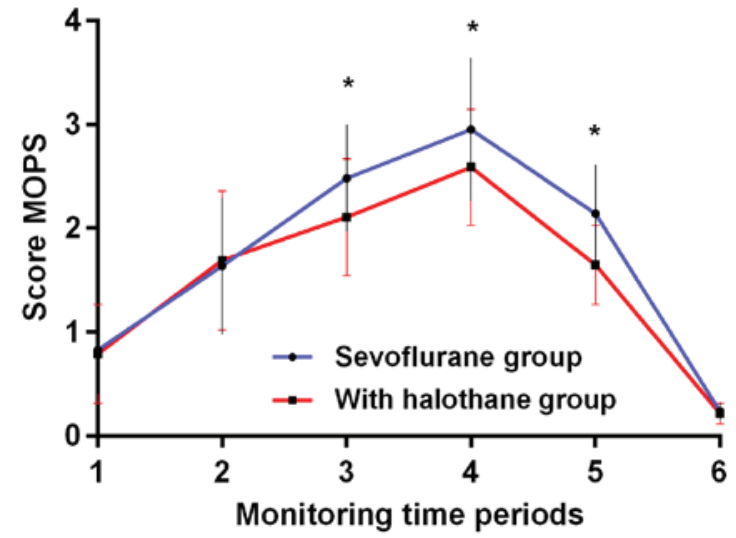

Figure 3. Comparison of MOPS scores of children between the groups. The pain of children in the two groups was evaluated according to MOPS. The results showed that at b1, b2 and b6, there was no significant difference in the MOPS of children between the sevoflurane group and the desflurane group $(\mathrm{P}>0.05)$. At b3, b4 and b5, children in the sevoflurane group had higher MOPS of children than those in the desflurane group $(\mathrm{P}<0.05)$. ${ }^{*} \mathrm{P}<0.05$, compared to the sevoflurane group, the difference is statistically significant.

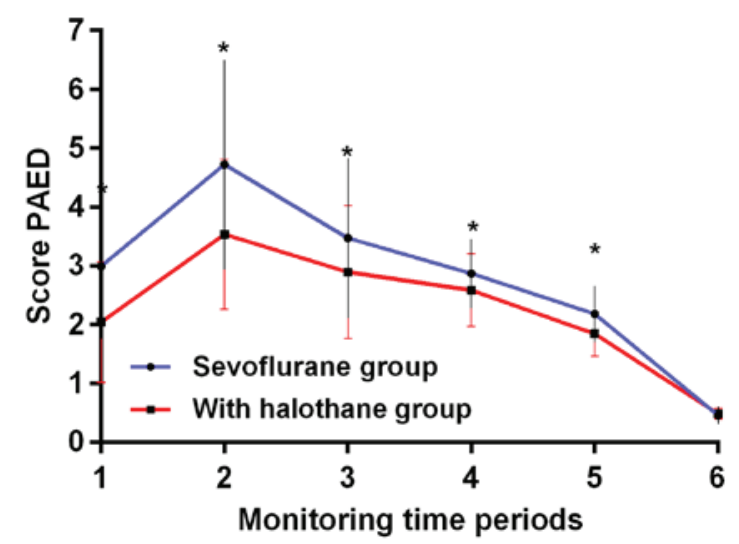

Figure 4. Comparison of PAED scores of children between the groups. The postoperative agitation of children in the two groups was evaluated according to MOPS. The results showed that at a6, there was no significant difference in the PAED scores of children between the sevoflurane group and the desflurane group $(\mathrm{P}>0.05)$. At a1, a2, a3, a4 and a5, children in the sevoflurane group had higher PAED scores than those in the desflurane group $(\mathrm{P}<0.05)$. ${ }^{*} \mathrm{P}<0.05$, compared to the sevoflurane group, the difference is statistically significant.

Postoperative pain of children in the two groups. The results of the study showed that at b1, b2 and b6, there was no significant difference in the MOPS of children between the sevoflurane group and the desflurane group $(\mathrm{P}>0.05)$. At b3, the MOPS of children was $2.48 \pm 0.52$ in the sevoflurane group, higher than the $2.11 \pm 0.56$ in the desflurane group $(\mathrm{t}=4.387$, $\mathrm{P}<0.001)$. At $\mathrm{b} 4$, the MOPS of children was $2.95 \pm 0.69$ in the sevoflurane group, higher than the $2.59 \pm 0.65$ in the desflurane group ( $\mathrm{t}=3.451, \mathrm{P}=0.001)$. At $\mathrm{b} 5$, the MOPS of children was $2.14 \pm 0.47$ in the sevoflurane group, higher than the $1.65 \pm 0.38$ in the desflurane group $(\mathrm{t}=7.390, \mathrm{p}<0.001)$ (Fig. 3).

Postoperative agitation of children in the two groups. The results of the study showed that at a6, there was no significant difference in the PAED scores of children between the 
sevoflurane group and the desflurane group $(\mathrm{P}>0.05)$. At a1, the PAED score of children was $2.99 \pm 1.23$ in the sevoflurane group, higher than the $2.04 \pm 1.03$ in the desflurane group $(\mathrm{t}=5.394, \mathrm{P}<0.001)$. At a2, the PAED score of children was $4.72 \pm 1.79$ in the sevoflurane group, higher than the $3.53 \pm 1.28$ in the desflurane group $(\mathrm{t}=4.942, \mathrm{P}<0.05)$. At a3, the PAED score of children was $3.47 \pm 1.36$ in the sevoflurane group, higher than the $2.89 \pm 1.13$ in the desflurane group $(\mathrm{t}=2.988, \mathrm{P}=0.003)$. At a4, the PAED score of children was $2.87 \pm 0.59$ in the sevoflurane group, higher than the $2.58 \pm 0.62$ in the desflurane group $(\mathrm{t}=3.072, \mathrm{P}=0.003)$. At a5, the PAED score of children was $2.18 \pm 0.48$ in the sevoflurane group, higher than the $1.84 \pm 0.38$ in the desflurane group $(\mathrm{t}=5.065, \mathrm{P}<0.001)$ (Fig. 4).

\section{Discussion}

In recent years, the number of children with tonsil and adenoid hypertrophy has increased significantly. Clinically, children with tonsil and adenoid hypertrophy are commonly treated with resection. Children are in a critical period of body growth and development, with poor compensation of the body and organ system and have poor operative compliance. Therefore, they have strong postoperative nociceptive stress response and emotional response, with poor postoperative recovery quality. Failure to obtain good postoperative recovery quality may lead to pain aggravation in children, and a series of side effects such as agitation, nausea, vomiting, and cerebral hypoxia, which may cause irreversible long-term physical and mental damage to children and prolong length of stay (19).

Clinically, the most commonly used inhalation general anesthesia for the pediatric operation is desflurane and sevoflurane. Desflurane, a fluoro-chlorinated compound of isoflurane with low blood and air partition coefficient, low blood solubility, quick recovery in children and good controllability, is an ideal inhalation anesthetic in pediatric anesthesia (20). However, it is highly irritating to the respiratory tract and cannot be used for anesthesia induction, which is often used to maintain anesthesia clinically. Sevoflurane has a fragrant smell, which is less irritating to the respiratory tract, and has no inhibitory effect on the circulatory system. Commonly used in younger children with poor treatment compliance, it can be used for anesthesia induction and maintenance, widely used in clinical practice (21). However, postoperative agitation caused by sevoflurane in children is very common (11). Sevoflurane is also highly volatile, and the anesthetic waste gas pollutes the environment, causing certain damage to the upper respiratory tract health of medical staff (22).

The results of the current study showed that there was no significant difference in the onset time of anesthesia of children between the sevoflurane group and the desflurane group ( $\mathrm{t}=1.122, \mathrm{P}=0.264)$. Children in the desflurane group had shorter operation time than those in the sevoflurane group $(\mathrm{t}=2.192, \mathrm{P}=0.030)$; shorter recovery time than those in the sevoflurane group $(\mathrm{t}=2.711, \mathrm{P}=0.007)$; shorter extubation time than those in the sevoflurane group $(\mathrm{t}=3.382, \mathrm{P}=0.001)$; shorter coincidence time than those in the sevoflurane group $(t=2.975$, $\mathrm{P}=0.003)$. This indicates that children in the desflurane group have a smoother operation, faster anesthesia recovery rate and better postoperative recovery in the short-term than those in the sevoflurane group. At t0, there were no significant differences in the NISBP and NIDBP of children between the sevoflurane group and the desflurane group $(\mathrm{P}>0.05)$. At $\mathrm{t} 1, \mathrm{t} 2, \mathrm{t} 3, \mathrm{t} 4, \mathrm{t} 5$ and $\mathrm{t} 6$, children in the sevoflurane group had higher NISBP and NIDBP than those in the desflurane group $(\mathrm{P}<0.05)$. The study by Lin et al $(23)$ found that after tracheal intubation with sevoflurane at a concentration of $8 \%$ for anesthesia maintenance, patients' DBP increases significantly. This is similar to our findings, indicating that sevoflurane has a certain impact on human blood pressure. At t0 and t6, there was no significant difference in the HR of children between the sevoflurane group and the desflurane group $(\mathrm{P}>0.05)$. At $\mathrm{t} 1, \mathrm{t} 2, \mathrm{t} 3, \mathrm{t} 4$ and $\mathrm{t} 5$, children in the sevoflurane group had lower HR than those in the desflurane group $(\mathrm{P}<0.05)$. In the study by Ishibashi et al (24), ketamine, sevoflurane and propofol for pediatric anesthesia induction were compared. It was found that the HR of children with sevoflurane for anesthesia induction is lower than that of children with ketamine and propofol. This is similar to our findings. Low HR can lead to a decrease in myocardial oxygen consumption, thereby limiting the contraction of peripheral blood vessels and resulting in insufficient blood supply to the body, which is not conducive to the postoperative recovery of children (25). At t0, t4, t5 and t6, there was no significant difference in the $\mathrm{SpO}_{2}$ of children between the sevoflurane group and the desflurane group $(\mathrm{P}>0.05)$. At $\mathrm{t} 1, \mathrm{t} 2$ and $\mathrm{t} 3$, children in the sevoflurane group had lower $\mathrm{SpO}_{2}$ than those in the desflurane group $(\mathrm{P}<0.05)$. Pellis et al (26) monitored patients who maintained anesthesia with desflurane and remifentanil during laparoscopic gastric bypass surgery. No significant fluctuation in the preoperative and postoperative $\mathrm{SpO}_{2}$ of patients was found. This is similar to our findings. In this study, the $\mathrm{SpO}_{2}$ of children who maintained anesthesia with desflurane was higher than that of children who maintained anesthesia with sevoflurane. This indicates that desflurane has no significant effect on the $\mathrm{SpO}_{2}$ level of children. The World Health Organization stated that $\mathrm{SpO}_{2}$ less than $90 \%$ can be regarded as hypoxemia in the body, which is not conducive to the postoperative recovery of children (27). At c1 and c5, there was no significant difference in the Ramsay scores of children between the sevoflurane group and the desflurane group ( $\mathrm{P}>0.05)$. At $\mathrm{c} 2, \mathrm{c} 3$ and $\mathrm{c} 4$, children in the sevoflurane group had lower Ramsay scores than those in the desflurane group $(\mathrm{P}<0.05)$. At a6, there was no significant difference in the PAED scores of children between the sevoflurane group and the desflurane group ( $\mathrm{P}>0.05)$. At a1, a2, a3, a4 and a5, children in the sevoflurane group had higher PAED scores than those in the desflurane group $(\mathrm{P}<0.05)$. The experimental results of Wang et al (28) show that if sevoflurane is used alone for pediatric anesthesia, the incidence of pediatric agitation is $50 \%$, and the excitement score is significantly higher than that of children with propofol for anesthesia. Our results showed that sevoflurane caused short-term agitation in children. However, with their self-recovery, and the comfort of their parents and doctors and nurses' care, their agitation gradually returned to normal. At $6 \mathrm{~h}$ after the tracheal catheter was extubated, the emotion of children in the sevoflurane group was basically the same as that of children in the desflurane group. Agitation during the postoperative recovery will affect children's postoperative recovery. Causing bleeding of the operative wound and 
physical damage to children, children's struggle may even lead to asphyxia and other serious life-threatening consequences. At b1, b2 and b6, there was no significant difference in the MOPS of children between the sevoflurane group and the desflurane group $(\mathrm{P}>0.05)$. At b3, b4 and b5, children in the sevoflurane group had higher MOPS than those in the desflurane group $(\mathrm{P}<0.05)$. It is speculated that children in the sevoflurane group are more agitated after operation, resulting in tearing of the wound and pain aggravation.

In summary, more suitable as an anesthetic maintenance drug for tonsillectomy and adenoidectomy in children, desflurane has a better anesthetic effect and is safer. In addition, children with desflurane anesthesia have high postoperative recovery quality and quick recovery in the short term, with better sedative and analgesic effects.

\section{Acknowledgements}

Not applicable.

\section{Funding}

No funding was received.

\section{Availability of data and materials}

The datasets used and/or analyzed during the present study are available from the corresponding author on reasonable request.

\section{Authors' contributions}

$\mathrm{XW}$ and CS were responsible for postoperative recovery quality analysis. BP collected the patients' general data. XS and FZ analyzed and interpreted NIBP, HR and $\mathrm{SpO}_{2}$. XW and JC contributed to statistical analysis. All authors read and approved the final manuscript.

\section{Ethics approval and consent to participate}

The study was approved by the Ethics Committee of Xuzhou Children's Hospital, Xuzhou Medical University (Xuzhou, China). Patients who participated in this research, had complete clinical data. Signed informed consents were obtained from the parents of the child patients or the guardians.

\section{Patient consent for publication}

Not applicable.

\section{Competing interests}

The authors declare that they have no competing interests.

\section{References}

1. Zagólski O: Why do palatine tonsils grow back after partial tonsillectomy in children? Eur Arch Otorhinolaryngol 267: 1613-1617, 2010

2. Anuntaseree W, Rookkapan K, Kuasirikul S and Thongsuksai P: Snoring and obstructive sleep apnea in Thai school-age children: Prevalence and predisposing factors. Pediatr Pulmonol 32: 222-227, 2001.
3. Gonzales R, Bartlett JG, Besser RE, Hickner JM, Hoffman JR and Sande MA; Centers for Disease Control and Prevention: Principles of appropriate antibiotic use for treatment of nonspecific upper respiratory tract infections in adults: Background. Ann Emerg Med 37: 698-702, 2001.

4. Mitchell RB, Garetz S, Moore RH, Rosen CL, Marcus CL, Katz ES, Arens R, Chervin RD, Paruthi S, Amin R, et al: The use of clinical parameters to predict obstructive sleep apnea syndrome severity in children: The Childhood Adenotonsillectomy (CHAT) study randomized clinical trial. JAMA Otolaryngol Head Neck Surg 141: 130-136, 2015.

5. Yazicı H: Nasal mucociliary clearance in adenoid hypertrophy and otitis media with effusion. Curr Allergy Asthma Rep 15: 74, 2015.

6. Karadağ S, Özkiriş M, Kubilay U and Söyletir G: The effect of radiofrequency ablation on microbiology of the tonsils. Int $\mathrm{J}$ Pediatr Otorhinolaryngol 76: 1654-1657, 2012.

7. Kim HJ, Park BK and Chung IS: Comparison of general anesthesia and conscious sedation during computed tomographyguided radiofrequency ablation of T1a renal cell carcinoma. Can Assoc Radiol J 69: 24-29, 2018.

8. Wormald PJ, van Renen G, Perks J, Jones JA and Langton-Hewer CD: The effect of the total intravenous anesthesia compared with inhalational anesthesia on the surgical field during endoscopic sinus surgery. Am J Rhinol 19: 514-520, 2005.

9. Kaskinoro K, Maksimow A, Georgiadis S, Långsjö J, Scheinin H, Karjalainen P and Jääskeläinen SK: Electroencephalogram reactivity to verbal command after dexmedetomidine, propofol and sevoflurane-induced unresponsiveness. Anaesthesia 70: 190-204, 2015.

10. Esper T, Wehner M, Meinecke CD and Rueffert H: Blood/Gas partition coefficients for isoflurane, sevoflurane, and desflurane in a clinically relevant patient population. Anesth Analg 120: 45-50, 2015.

11. Guler G, Akin A, Tosun Z, Ors S, Esmaoglu A and Boyaci A: Single-dose dexmedetomidine reduces agitation and provides smooth extubation after pediatric adenotonsillectomy. Paediatr Anaesth 15: 762-766, 2005.

12. Xu X, Zheng C, Li N, Shen $\mathrm{H}$ and Wang G: The decrease of NMDAR subunit expression and NMDAR EPSC in hippocampus by neonatal exposure to desflurane in mice. Behav Brain Res 317: 82-87, 2017.

13. Demirel I, Ozer AB, Bayar MK and Erhan OL: Anaesthesia management for acute appendicitis in cases with Sjogren's syndrome accompanying autoimmune hepatitis. BMJ Case Rep 2013: pii: bcr2012008111, 2013.

14. Yildirim H, Adanir T, Atay A, Katircioğlu K and Savaci S: The effects of sevoflurane, isoflurane and desflurane on QT interval of the ECG. Eur J Anaesthesiol 21: 566-570, 2004.

15. Zeng G, Zhao Z, Yang F, Zhong W, Wu W and Chen W: Retrograde intrarenal surgery with combined spinal-epidural vs general anesthesia: A prospective randomized controlled trial. J Endourol 29: 401-405, 2015.

16. Hsu CW, Sun SF, Chu KA, Lee DL and Wong KF: Monitoring sedation for bronchoscopy in mechanically ventilated patients by using the Ramsay sedation scale versus auditory-evoked potentials. BMC Pulm Med 14: 15, 2014.

17. Buonsenso D, Barone G, Valentini P, Pierri F, Riccardi R and Chiaretti A: Utility of intranasal Ketamine and Midazolam to perform gastric aspirates in children: A double-blind, placebo controlled, randomized study. BMC Pediatr 14: 67, 2014.

18. Locatelli BG, Ingelmo PM, Emre S, Meroni V, Minardi C, Frawley G, Benigni A, Di Marco S, Spotti A, Busi I, et al: Emergence delirium in children: A comparison of sevoflurane and desflurane anesthesia using the Paediatric Anesthesia Emergence Delirium scale. Paediatr Anaesth 23: 301-308, 2013.

19. Yilmaz T, Koçan EG and Besler HT: The role of oxidants and antioxidants in chronic tonsillitis and adenoid hypertrophy in children. Int J Pediatr Otorhinolaryngol 68: 1053-1058, 2004.

20. Dalal KS, Choudhary MV, Palsania AJ and Toal PV: Desflurane for ambulatory anaesthesia: A comparison with sevoflurane for recovery profile and airway responses. Indian $\mathrm{J}$ Anaesth 61: 315-320, 2017.

21. Amin AM, Mohammad MY and Ibrahim MF: Comparative study of neuromuscular blocking and hemodynamic effects of rocuronium and cisatracurium under sevoflurane or total intravenous anesthesia. Middle East J Anaesthesiol 20: 39-51, 2009.

22. Krenzischek DA, Schaefer J, Nolan M, Bukowski J, Twilley M, Bernacki E and Dorman T: Phase I collaborative pilot study: Waste anesthetic gas levels in the PACU. J Perianesth Nurs 17: 227-239, 2002. 
23. Lin TC, Lu CC, Kuo CK, Hsu CH, Huang GS, Liu JY and Ho ST: Single vital-capacity and successive tidal-volume breathing of sevoflurane in induction of anesthesia for tracheal intubation in gynecologic patients. Acta Anaesthesiol Taiwan 46: 66-70, 2008.

24. Ishibashi H: More effective induction of anesthesia using midazolam-butorphanol-ketamine-sevoflurane compared with ketamine-sevoflurane in the common marmoset monkey (Callithrix jacchus). J Vet Med Sci 78: 317-319, 2016.

25. Schaller BJ, Sandu N, Cornelius JF, Filis A and Perez-Pinzon MA; Trigemino-Cardiac-Reflex-Examination-Group (T.C.R.E.G.): Oxygen-conserving implications of the trigemino-cardiac reflex in the brain: The molecular basis of neuroprotection? Mol Med 15: 125-126, 2009.

26. Pellis T, Leykin Y, Albano G, Zannier G, Di Capua G, Marzano B and Gullo A: Perioperative management and monitoring of a super-obese patient. Obes Surg 14: 1423-1427, 2004.
27. Yoder BA, Stoddard RA, Li M, King J, Dirnberger DR and Abbasi S: Heated, humidified high-flow nasal cannula versus nasal CPAP for respiratory support in neonates. Pediatrics 131: e1482-e1490, 2013.

28. Wang X, Jiang T and Zhao B: Effects of different maintain doses of dexmedetomidine on plasma cortisol and glucose during anesthesia recovery period in patients undergoing uvulopalatopharyngoplasty under sevoflurane inhalation anesthesia. Lin Chung Er Bi Yan Hou Tou Jing Wai Ke Za Zhi 28: 1154-1157, 2014 (In Chinese).

This work is licensed under a Creative Commons Attribution-NonCommercial-NoDerivatives 4.0 International (CC BY-NC-ND 4.0) License. 